\title{
The Reduction of FWM effects using Duobinary Modulation in a Two-Channel D-WDM System
}

\author{
Laxman Tawade ${ }^{1}$, Balasaheb Deokate ${ }^{2}$ \\ Department of Electronic and Telecommunication Vidya Pratishthan's College of \\ Engineering Baramati, Pune University, Vidyanagri Bhigwan Road Baramati, \\ Pune, 413133, India , (Phone) +91-9730438571. \\ E-mail: tawadelaxman@rediffmail.com, b_ash11@rediffmail.com
}

\begin{abstract}
This papers show that the adoption of a duo binary Modulation scheme reduces the impact of FWM in a DWDM system. The levels of the FWM products are reduced by around $10 \mathrm{~dB}$ which will offer a significant performance benefit in digital systems. We have taken into consideration great demand for high data rate \& have designed optical fiber system for 40 Gbps.
\end{abstract}

Keywords-dispersion shifted fiber (DSF), Dense wavelength division multiplexing (DWDM), Four wave mixing $(F W M)$, Bit error rate (BER).

\section{Introduction}

In order to meet the huge capacity demands imposed on the core transmission network by the explosive growth in data communications the number of optical channels in dense-WDM optical networks is being increased. Since the gain bandwidth of EDFAs is limited, these requirements for a very large number of channels means that he channel spacing will have to be small. The current ITU grid specifies $100 \mathrm{GHz}$ channel spacing, but systems are being considered with 50 $\mathrm{GHz}$ to $25 \mathrm{GHz}$ channel spacing. At these spacing, the non-linear effects of the optical fibre can induce serious system impairments and modulation schemes are now being developed which are robust to both the linear and non-linear behaviour of fibre. Duobinary modulation techniques are known to compress the optical spectrum, thereby facilitating the tighter packing of channels into the EDFA gain window. It has also been reported that the 2- level variant of duo binary signaling [1,2] almost eliminates the impact of SBS since the optical carrier component is suppressed [3]. Four-Wave-Mixing (FWM) is another non linear effect that can limit the performance of WDM systems [4,5]. In this paper, we experimentally demonstrate that a 2-level duo binary modulation format suppresses the FWM non-linear effects in two closely spaced WDM channels. This is particularly prevalent in optical networks employing dispersion shifted fibre (DSF) [6]. To our knowledge, this is the first experimental demonstration of same. The experimental setup is validated using simulation software Optisystem. 


\section{Experimental Set up}

Two experiments were conducted; one was to determine the level of FWM products in a conventional binary modulated system, and one to determine the level of the FWM products in a 2-level duo binary system. The average launch power was kept as constant as practicable for all of the experiments. The experimental set-up is shown in figure 1. A pattern generator drives the optical transmitter in both experiments. The pattern generator produces a PRBS at a bit rate of $40 \mathrm{Gbit} / \mathrm{s}$. we have used CW LASER 1 which is operating at wavelength $1552 \mathrm{~nm} \&$ given power is $4 \mathrm{mw}$ the optical transmitter generates a modulated optical signal (binary or duobinary depending on the experiment) which is combined with the second unmodulated optical carrier in the $2 \mathrm{~dB}$ optical combiner. Second CW LASER 2 operating at wavelength $1551 \mathrm{~nm} \&$ given power is $3 \mathrm{mw}$. An EDFA follows the coupler to increase the launch power into the fibre to $+10 \mathrm{dBm}$. The signals are then transported over $25 \mathrm{~km}$ of DSF operating at close to zero dispersion. DSF is used in this experiment to enable the observation of a significant non-linear effect without

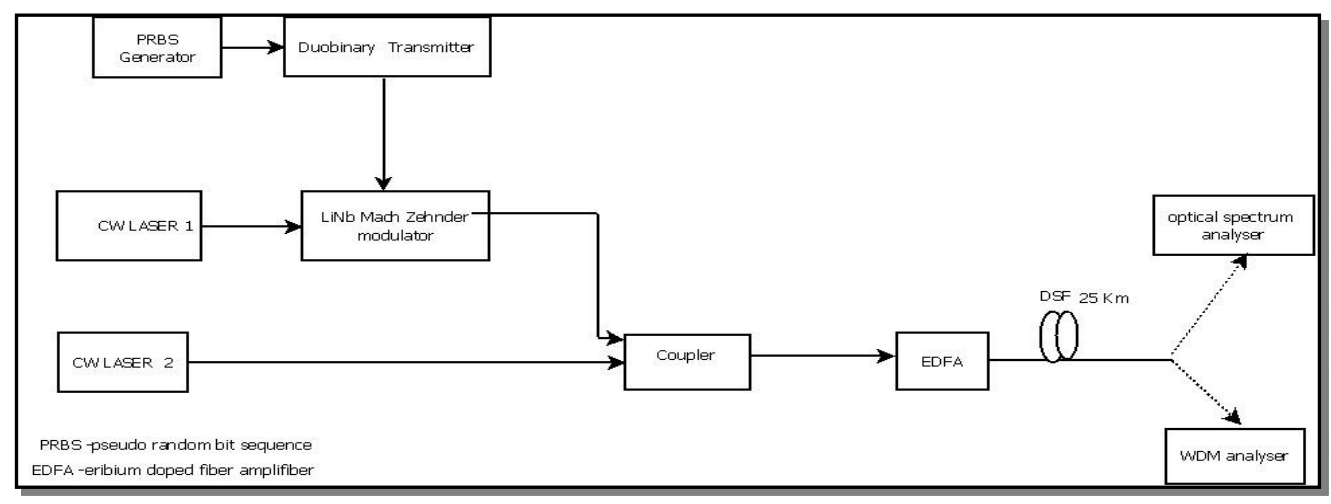

Figure 1. The Experimental setup

requiring a very long fiber span. In this experiment DSF having dispersion factor $0.63 \mathrm{ps} / \mathrm{nm} / \mathrm{km}[7]$. The spectrum after propagation through the DSF is viewed on an optical spectrum analyser (OSA). The duo binary encoder used consisted of a one-bit delay line. The output of the delay line was added to the original signal to generate a zero mean, three-level signal. This signal was amplified and applied to a single drive, balanced Mach-Zehender modulator that was biased at minimum transmission. This generated a two level optical signal which exhibited a $\pi$ phase shift in the optical field for the two extremes of the three level signals. Since the input data sequence was a PRBS there was no need to include a differential encoding pre coding stage as would be used with random data.

\section{Result}

With a channel spacing of $1 \mathrm{~nm}$ the level of the first-order FWM products were measured for both the binary and the duo binary case. Figure 2.1 and 2.2 shows the spectrum plots obtained with the optical spectrum analyzer and Table 1 gives the numerical values of the levels of the four components marked P1 to P4 in the figure. P1, P2 are the carriers and P3, P4 are the FWM products. As in this experiment we have used CW laser 1 which is operating at $1552 \mathrm{~nm}$ i.e in terms of frequency $\mathrm{W}_{1}=193.165243 \mathrm{THz} \& \mathrm{CW}$ laser 2 operating at $1551 \mathrm{~nm}$ i.e in terms of frequency $\mathrm{W}_{2}=193.2897 \mathrm{THz}$. Because of FWM effect we observe two unwanted FWM product at 
International Journal of Distributed and Parallel Systems (IJDPS) Vol.2, No.6, November 2011

$$
\begin{array}{lll}
\mathrm{P} 3 & \text { at } 2 \mathrm{~W}_{1}-\mathrm{W}_{2} \\
\mathrm{P} 4 & \text { at } 2 \mathrm{~W}_{2}-\mathrm{W}_{1}
\end{array}
$$

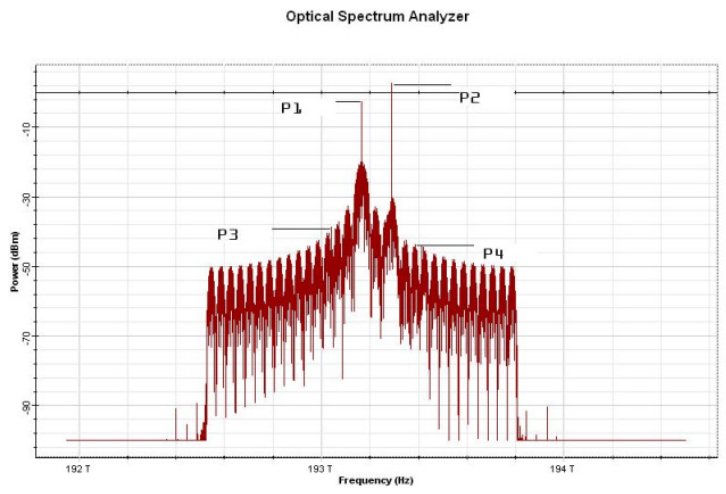

Figure 2.1.Spectral plot at fiber output for binary modulation

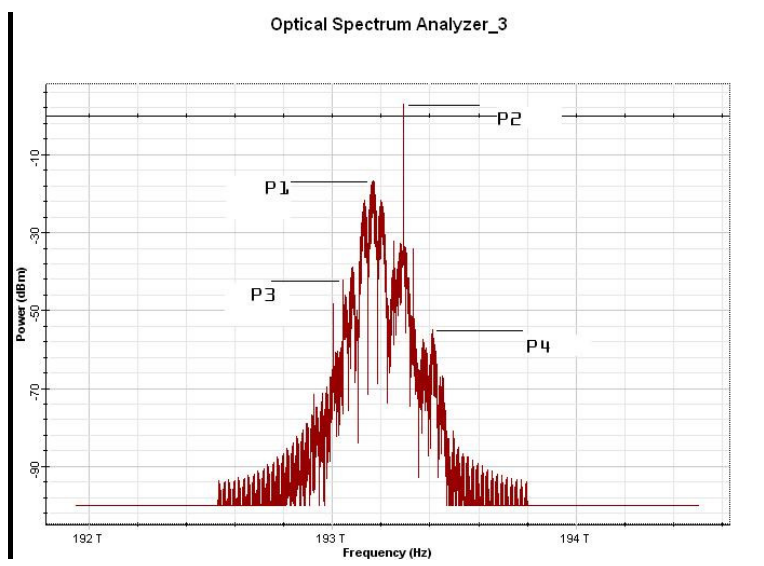

\begin{tabular}{|c|c|c|c|c|}
\hline $\begin{array}{r}\mathrm{I} \\
(\mathrm{dBm}\end{array}$ & $\begin{array}{l}\text { P1 } \\
\text { n) }\end{array}$ & $\begin{array}{l}\text { P2 } \\
\text { m) }\end{array}$ & $\begin{array}{c}\mathrm{P} 3 \\
(\mathrm{dBm})\end{array}$ & $\begin{array}{l}\text { P4 } \\
(\mathrm{dBm})\end{array}$ \\
\hline Binary & -2.39946 & 2.7133 & -38.6648 & -44.1354 \\
\hline Duobinary & $y-16.6742$ & 2.98635 & -42.5242 & -54.539 \\
\hline Table 1: levels & ls of the optic & ignals in $t$ & binary and & ıobinary case \\
\hline
\end{tabular}

Figure 2.2. Spectral plot at fiber output for duobinary modulation

The above results show that duobinary coding suppresses the FWM products by $3.8594 \mathrm{~dB}$ in the P3 case and $10.4036 \mathrm{~dB}$ in the P4 case. As a further experiment, the dependency of the suppression of the FWM products on the optical carrier spacing was investigated. The channel spacing was varied from $0.25 \mathrm{~nm}$ to $1 \mathrm{~nm}$ for both the binary and duo binary cases. The results 
International Journal of Distributed and Parallel Systems (IJDPS) Vol.2, No.6, November 2011 presented in figure 3 shows how the average level of the FWM products relative to the average levels of the two optical carriers varies over this channel spacing range. As can be seen, the adoption of duobinary gains suppression in FWM product ranging from around $10 \mathrm{~dB}$ to around $1 \mathrm{~dB}$, over this range of separations.

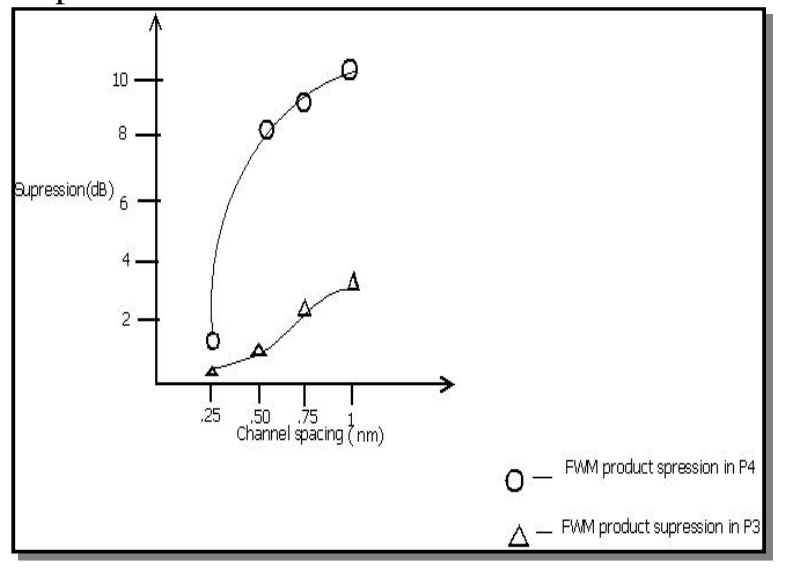

Figure 3. Average suppression of FWM product relative to channel spacing

\section{Conclusion}

This experiment provides experimental verification that the use of a duobinary encoding scheme can reduce significantly the level of four-wave mixing products. The suppression observed varied from $10 \mathrm{~dB}$ to $1 \mathrm{~dB}$, depending on the channel spacing. The suppression is greater for narrower channel spacing which suggests that as DWDM systems reach higher channel counts duobinary becomes a very attractive encoding method. This is not only because of its narrower spectral width and consequently greater tolerance to dispersion and narrower channel spacing possibilities, but also because of its already proven SBS tolerance, and, as shown in this paper, its tolerance to FWM effects.

\section{References}

[1] T. Franck, P.B. Hansen, T.N. Nielsen, L. Eskildsen, .Duobinary Transmitter with Low Intersymbol Interference. IEEE Photon. Technol. Lett., Vol. 10, No. 4, April 1998.

[2] T. Ono, Y. Yano, K. Fukuchi, T. Ito, H. Yamazaki, M. Yamaguchi, K. Emura, .Characteristics of Optical Duobinary Signals in Terabit/s Capacity, High-Spectral Efficiency WDM Systems., J. Lightwave Tech, Vol. 16, No. 5, May 1998.

[3] T. Franck, T. N. Nielsen, A. Stentz, .Experimental Verification of SBS Suppression by Duobinary Modulation., ECOC 97, September 1997.

[4] K. Inoue, .Influence of fiber FWM in multichannel return-to-zero signal transmissions., IEEE Photon. Technol. Lett. Vol. 8, 1996.

[5] N. Shibata, K. Nosu, K. Iwashita, Y. Azuma, .Transmission Limitations Due to Fiber Nonlinearities in Optical FDM Systems., IEEE Journal of Selected Areas in Commun., Vol.8, No.6, 1999

[6] D. Hjelme, J. Eide, B. Slagsvold, .FWM Efficiency in Installed Dispersion Shifted Fibers: Effects of zerodispersion wavelength variations. OFC 1998.

[7] Kazuhide Nakajima, Masaharu Ohashi, Kazuyuki Shiraki, Tsuneo Horiguchi "Four-Wave Mixing Suppression Effect of Dispersion Distributed Fibers” JOURNAL OF LIGHTWAVE TECHNOLOGY, VOL. 17, NO. 10, OCTOBER 1999 


\section{Authors}

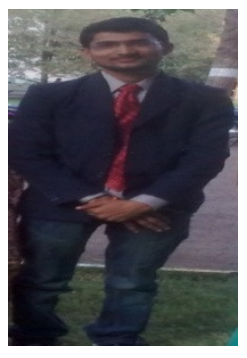

Laxman Tawade has pursued BE degree in Electronic \& Telecommunication from Pune University, India in 2011. Currently he is member of International Association of Computer Science and Information Technology (IACSIT), Academy \& industry research collaboration center (AIRCC) \& Affiliate member of signal processing for communication and networking technical comitee. He has 1 paper in international conference and 4 papers in International Journal to his credit. He has worked as Reviewer for international journals and international conference sponsored by IEEE $\&$ also worked as program committee member of few international conferences. His research interest includes optical fiber communication and optical access networks based on WDM-PON, Biomedical signal processing.

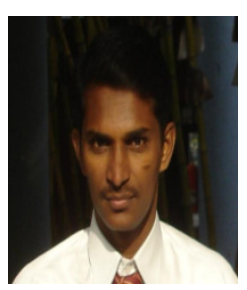

Deokate Balasaheb is currently an Assistant professor in the Department of Electronic \& Telecommunication at Vidya Pratishthan's College of Engineering, Baramati, India. He received M.E. in E\&Tc (Microwave) from Pune University in 2010 .His teaching experience is 5 years. He has 5 International conference papers. His research interest includes lightwave systems and optical access networks based on WDM-PON, VLSI, and digital system. 